Journal of Economics and Behavioral Studies

Vol. 6, No. 10, pp. 824-828, October 2014 (ISSN: 2220-6140)

\title{
Socio-Economic Sistemology: Multidimensional Science for a Comprehensive Study of the Socio-Economic and Legal System
}

\author{
${ }^{1}$ Shokhazamiy Shokhmansur*, AlisherBagbekov², Elmuradov D. ${ }^{3}$ \\ ${ }^{1}$ Tashkent Financial Institute, Uzbekistan \\ ${ }^{2}$ Capital Invest Ltd., Uzbekistan \\ ${ }^{3}$ University Malaysia Perlis (UniMAP), Malaysia \\ *shohmansur56@yandex.ru
}

\begin{abstract}
The main feature of the development of science in the second half of the 20th century was the transition from a single-dimensional science of past centuries, based mainly on experimentation, to the science of two dimensional, which is based on a systems approach. However, the conditions and trends of development of the world economy and society, therefore, the humanities and social sciences, including economics, in the twenty-first century calls for transition to new more advanced phase of science to integrated presentation and study in the relationship between the various components of the socio-economic and legal systems (SELS) based on a systematic approach. The importance of this completely new paradigm of science-its transition from two dimension in the multi dimension in general socio-economic and legal space is already quite fully understood, because it is based a well elaborated the theoretical-methodological and practical implications for the future of the base, a it seems extremely profound and promising.
\end{abstract}

Keywords: Social-economic systemology, social-economic-law system and its elements, equivalence, macroregulator, system-metric analysis and metrics

\section{Introduction}

This science, socio-economic sistemology on the basis of economic development in breadth and depth, systemology cannot be directly compared with other sciences, and it would be better to treat it as a multidimensional measurement in modern science (Shokhazamiy, 2010, 2012). And socio-economic sistemology can provisionally be called multi science of SELS. It as a multidimensional measurement of the overall socio-economic information and the legal relationship applies the symbiosis of many Sciences such as, for example, the theory of law, mathematics, statistics, information theory and management, sociology, economics, information technology, the theory of analogy and other sciences, which together provide the ability to systematically study the SELS. Therefore, we can say that the overall socio-economic sistemology as multi science is studying the SELS with the consistency and comprehensiveness. It should be noted that the application of a systematic approach to studying SELS and its subsystems as a complex system of various configuration and level of consistency and integrity, gives the possibility to use achievements of many sciences, which are also based on this approach. Therefore, it is useful to look at this interrelated intelligent design, applied in socio-economic systemology as to different parts of the more common field system research. This field may be called total field composed of many interrelated dimensions to the above science, applying a systems approach. Socio-economic sistemology, based on a systems approach to the study of SELS as a complex system, composed of different nature (characters, entity types and relationships appointments, infrastructures, functions, properties, and so on), but equivalent, subsystems in macro regulation their relationship, which as any science has:

- Concepts and terminology apparatus for objects of systematic research and studying the sciences

- The knowledge about the subject areas and objects

- Methodology (a set of agreed methods) the accumulation of new knowledge about these areas and use this knowledge to solve related issues and challenges

\section{Concepts of socio-economic systemology}

The SELS as complex system consists of different nature and regulatory interrelated subsystems (Figure 1), 
each of which possesses a characteristic only for the type of entities and relationships. In particular, Figure 1 is subsystems like the social subsystem (SS), the judicial subsystem (JSS), economic subsystem (ES), which includes the sector of production and reproduction (SPR) system financial-credit resources (with the exception of the financial market), the subsystem of national market (SNM) as a subsystem of supply and demand, the macro-regulations (MR). In the socio-economic systemology approaches can be applied bottomup and top-down. These concepts are synonymous with the concepts of the specific to the general, and from the general to the specific concepts. Socio-economic sistemology, applying the above famous symbiosis of science, exploring the SELS as a complex system, adapts to the influences of external and internal factors through macro-regulators (MR). Therefore, in figure $1 \mathrm{MR}$ can be regarded as a subsystem of the integrated balancing equivalent subsystems-SS, JSS, ES and SNM- depending on the factors, which should be aimed at ensuring the balanced development of the SELS.

Figure 1: Theoretical and spatial representation of socio-economic systemology SELS as the structural-functional macro models with complex strongly associated subsystems.

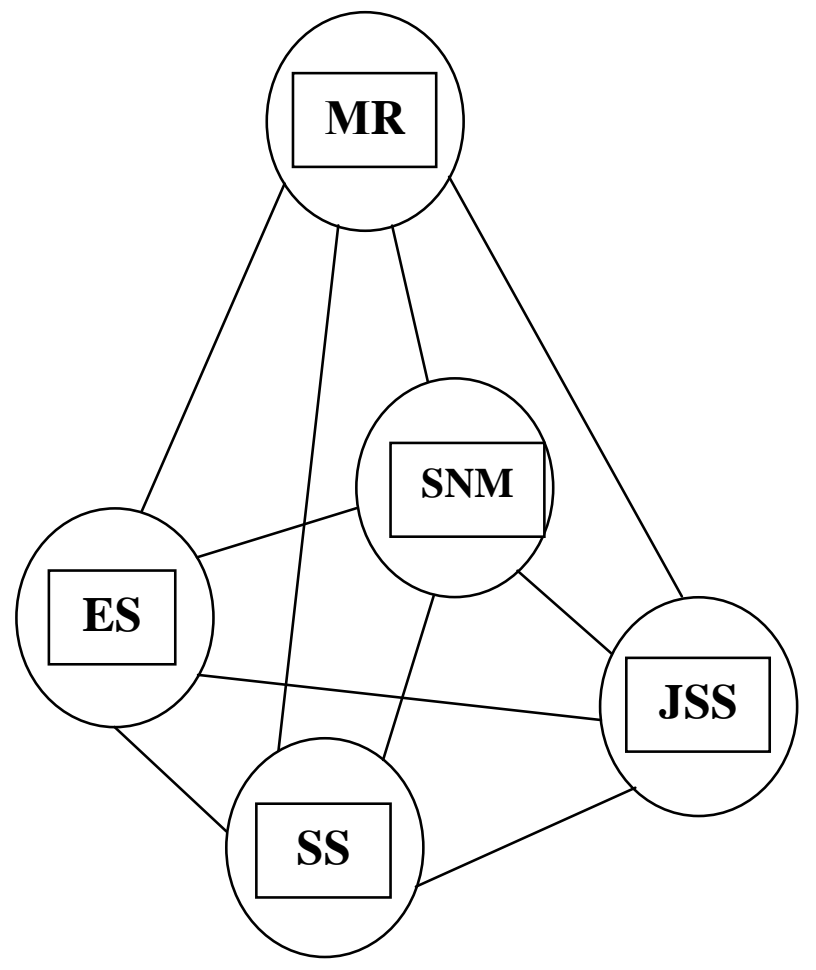

In terms of differences in the nature of subsystems (MR, SS, JSS, ES, and SNM) can be divided into three categories:

-Market subsystems (MS), consisting of SS and JSS;

-Non-market subsystems (NMS), consisting of ES and SNM;

-MR like macro regulation subsystem integrated trim equivalent of MS and NMS.

\section{Relationship between Market Subsystem and Non-market Subsystem in Socio-economic and Legal Systems}

The integrated trim equivalent of MS and NMS in SELS based on the theory of "equilibrated quasi analogue" that have common MR, means to achieve the common objective of balanced development of these subsystems (Shokhazamiy, 2010). This is equivalent to a balanced development in all spheres of social, economic, legal, political, etc. The process of achieving such development is characterized by SELS indicator variable system that is determined by the effects of the external and internal factors. Hence, the result of balanced 
development (RBD) SELS can be represented as a function that depends on the MS and NMS:

$R B D=f(M S, N M S)(1)$

If we consider the function (1) as a generalized mathematical model, then the derivative of this function as (2) represents a further increase in the level of RBD from an economic point of view.

$$
R B D=\left(\frac{R B D}{M S}\right) \times M S+\left(\frac{R B D}{N M S}\right) \times N M S
$$

Since each of the subsystems (MS, NMS) has its own type of entities and relationships, from the perspective of economic systemology just schema model presented in Figure 2

Figure 2: Structural-functional model of SELS, composed of interrelated MS and NMS with general macro regulator (MR)

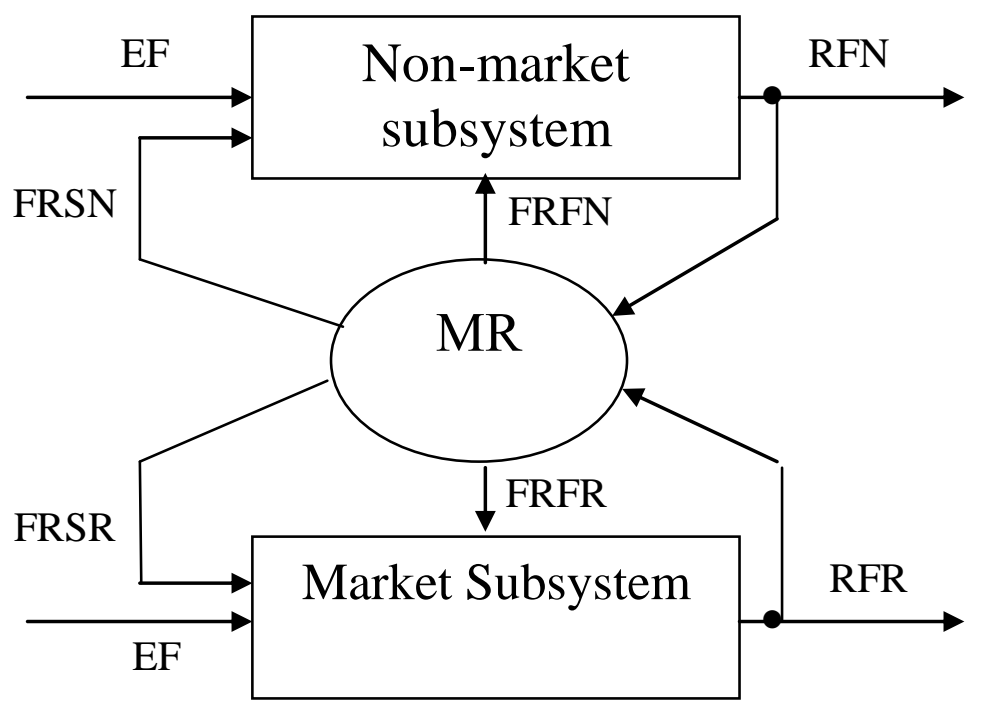

The Figure 2 MS and NMS are equivalent because of the mathematical proof of equivalency (analogy), two similar but different by nature, shared MR subsystems (Shokhazamiy, 2010). It should be noted that, contrary to the equivalence between the MS and NMS, as well as the ineffectiveness of one of them, can lead to crises in SELS, which manifest themselves in the form of adverse events across all subsystems. Due to the equivalence principle, applied in the theory of "equilibrated quasi analogue" model, can be explored the NMS through the properties and patterns inherent in the processes taking place in the register of enterprises, and the factors shaping the development of phenomena specific to the MS. This is one of the important provisions of the socio-economic systemology, which allows carrying out an economic analysis of the effectiveness of the NMS. Macro model presented on Figure 1, visioning can demonstrate that economic sistemology as multidimensional science, which provides ample opportunities to systematically study the SELS, composed of complex macro regulation in the relationship equivalent of subsystems-market (ES and NM) and non-market (SS, JS, MR). These features are due to the fact that:

- -Economic sistemology studies on the basis of systematic study of the adjustability, SELS, which is a complex adapts to the influences of various factors (Figure 1), which consists of five equivalent and strongly related, but different by nature larger subsystems;

- -Depending on the level of aggregation of SELS system study and measurement of the SELS can be carried out at the global (meta)-, international meso (regional)-, macro-, inside countries meso-, micro-and nano scale levels;

- -Integrated action of subsystems is subordinated to the common goal of a sustainable and peaceful socio-economic development of the country on the basis of the chosen people of the development 
model, which provides all the subsystems under general MR.

- $\quad$-The functioning of each subsystem SELS ordered its special economic and legal framework. Each of these mechanisms subordinate to the overall goal of SELS;

- $\quad$-It can be seen that the direction of the subsystems of the SELS are synchronous and corresponds N. Kondratieva's cycle. The oscillating motion of financial-credit sector ahead of time a similar movement from other subsystems;

- -For systems analysis is complex estimation of influence of various factors, targeted approach to their study. The knowledge factors, the ability to determine their impact on the quality indicators allow you to influence the level of indicators through the management factors, to establish a mechanism for finding solutions;

- $\quad$-Each subsystem SELS and its phenomena and processes possess certain properties and regularities;

- $\quad$ The quality and achieve the degree of completeness that SELS common objective have generally accepted indicators system and evaluated expressing the results of functioning of the sub-systems in their regulatory relationships;

- -System analysis applied the generic mathematical apparatus and methods of statistics, standard information base statistical indicators (indicators) that you can use to build appropriate models, to take into account the properties and patterns, the nature of each subsystem;

- -Socio-economic systemology system-metric analysis and measurement of qualitative and quantitative changes in each subsystem has its own object-oriented science. In particular, for systemmetric analysis and measurement qualitative and quantitative changes in the real sector of economy (LEN) applied econometrics, financial-credit area (including financial market)-finance metric, in the securities market in the financial market-secure metric, in the market of real goods and non-financial services-the market metric that make up the MS (Greene, 1997, Verbeek, 2000). While the SS is sociometric and JS is juridical-metric (Law metrics), which are NMS. In MR applies qualification-metric regulators, which is closely related to integrated quality management system of the real product, the help of quality control based on real products and non-financial services, as well as integrated quality management system of finance based on the financial help of quality control (Fayghenbaum, 1986);

- -Quantification of the degree of interconnection of subsystems on the selected indicators characterizes the degree of equivalence the subsystems, and the greater the correlation between subsystems, the higher their interaction, thus more efficiency in the total development of the SELS (economic and other kinds of growth), respectively, above the quality of macro regulation measures for the improvement or development of subsystems on these indicators;

- $\quad$-In the last 5 years (2009-2013) there has been a stronger effect of factors of non-market subsystems (e.g., CPI growth, human capital, innovation) on behavior and development. Hence, the obvious becomes equal interaction factors of MS and NMS in SELS, respectively, of the equivalence of subsystems, factors and phenomena (the law of Archimedes). The effects of NMS are directly reflected in results the functioning of the MS, therefore, are used in the socio-economic world and systemology analysis methodology and principles for evaluation of economic efficiency of NMS (SS, JS) and MR.

- -Important the value in the study and development of MS in conjunction with NMS has categories such as fair value, fundamental value, objective price, and their degree of equivalence. In modern conditions (in force events and lessons related to processes of financial globalization and the global financial and economic crisis) is the company's management policy is aimed at achieving growth in the fair value of the company in According to the fundamental value of the company's growth equivalent and an objective price of its shares;

- -Correlation and regression analysis of the relationship of one of the selected subsystem (by characteristic $s$ indicators) other subsystems (by characteristic of indicators) expresses the functional dependence of the selected subsystem and other subsystems in the form of regression equations. This makes it possible to build a common mathematical model SELS, including mathematical models of MR, SS, JS, ES, NM, each of which is associated with other subsystems (Figure 1).

- Presented in Figure 1 and Figure 2 conceptual models are complex dynamic system self-development with the central element of the overall macro regulation. In the model presented in Figure 2, balancing quasi analogue (MS and NMS), SELS, regulation is tantamount to a form of strong public- 
public socio-economic-information-legal regulation of both MS and NMS. It is in this vein should be organized by the modern national macro regulation SELS on Figure 2, the can greatly influence the nature of the legal and democratic development of the society, the business climate in the country and country rankings.

\section{Conclusion}

All this is very important because of the events in the developing world, particularly in Ukraine, where SELS because of its imperfection, macro regulations, unlike Uzbekistan, allow negative direct intervention large (oligarchic) capital (LC) in the socio-political and economic processes. On against this background, the following patterns for developing countries, where MR is weak. When loyalty (neutrality) LCand MS as ES behave spontaneously. When LC starts to interfere with ES, the ES becomes submissive for LC. In times of financial and economic crises LC volume to grow at least two times the liquidity through redeployment from the EStoLC. This leads to several monetary authorities additional liquidity in ES. After the crisis of the LC back pours its liquidity (in the form of big private capital) in the ES, which leads to the enrichment of the LC, an increase in liquidity and the rise of another crisis in the ES. Through monetary easing in developed countries the amount of liquidity continues to grow rapidly, but its cost is proportional to the decline and inflation is rising (in the best case is held at a relatively high level) in the developing countries.

LC makes be submissive ES by LC redistributes your capital in the following ratio (the Pareto principle):

- $\quad-20 \%$ of the real sector of the ES;

- $\quad-80 \%$ should hold in its speculative investment portfolio (SIP) for the purposes of hegemony and management of global ES, as a consequence, the behavior of planetary life (social, political, cultural, military, etc.). With this portfolio as "cash cloud aloft over the real economy of ES, called in the global currency, credit, stock, insurance markets, forming bubbles in the world financial market.

Therefore, the twenty-first century is a LC century of world domination. Because of these patterns, it must convince the LC whether to invest their private capital (at least 50\%) from SIP in innovation and transfer. This will automatically lead to the materialization of half SIP (useless for real economy "cloud money") LC in human capital (education and science) and the real sector of the ES. Accordingly, there will be a significant increase in the real capital (core capital), the welfare of the population, human capital and innovation.

Acknowledgement: This article dedicated to science minds and opportunities of social-economic systemology for complex studying of social-economic-law system.

\section{References}

Fayghenbaum, A. (1986). Product Quality Control. p-471.

Greene, W. H. (1997). Econometric Analysis, $3^{\text {rd }}$ Edition. Prentice-Hall, Upper Saddle River, New Jersey.

Shokhazamiy, S. (2010). Economic systemology: concept and application. Tashkent, p-420.

Shokhazamiy, S. (2012). Theory of property, value and price. Tashkent, p-248.

Shokhazamiy, S. (2012). Engineering of systematic finance. Tashkent, p-796.

Shokhazamiy, S. (2012). Systematic development of the securities market regulatory relationship with the real economy. Tashkent, p-448.

Shokhazamiy, S. (2012). Financial market and securities. Tashkent, p-440.

Verbeek, M. (2000). A Guide to Modern Econometrics. Wiley, Chichester. 